\title{
The Artistic Features of Li Yu's Poem
}

\author{
Yan Wang \\ Baicheng Normal College, Literature College, Baicheng, Jilin, China, 137000
}

Keywords: Li Yu, Word, Artistic Characteristics, Emotion

\begin{abstract}
During the Five Dynasties, there were a few words by the general scholar as "Southern Tang Ci", and $\mathrm{Li} \mathrm{Yu}$, one of the Southern Tang Dynasty, was one of the most significant achievements. Li Yu words to their own the most real, sincere feelings and the outside world of the specific scene and kind of a perfect fusion, the integration of the King and things, and with real rustic, natural plain language to express, and thus create a very artistic characteristics and charm of the works, by future generations spread forever. This paper analyzes the artistic characteristics of $\mathrm{Li}$ Yu's poems from the four aspects of lyricism, language, emotion change and image combination, taking $\mathrm{Li}$ Yu's $\mathrm{Ci}$ as the research object and taking $\mathrm{Li}$ Yu's artistic characteristics as the research goal. First of all, Li Yu words in the lyrical aspects of the performance of "straight express, natural unrestrained" and "magnificent hidden resentment, ethereal ho dang" artistic characteristics. Li Yu words emotion sincere, writing rate really to be able to carry out their feelings of the most frank expression. Secondly, Li Yu words in the language has a "real simplicity, straightforward spirit" and "good use of proverbs, metaphor refined" artistic characteristics. Li Yu words with the most close to life and the most authentic language, understand the words of their emotions will be expressed. Again, Li Yu words in their emotional changes, the performance of the pre-words of the beautiful luxury and the late words of the pain of subjugation. In addition, Li Yu words in the image combination, the performance of the pre-word joy and the late words of the sad and desolate.
\end{abstract}

\section{The Lyric Features of Li Yu's Words}

During the late Tang and Five Dynasties, the text for a variety of modification and carving, which is a large part of the words of the lyrics tendencies and in its emotional expression, but also more focused on the tactful lingering lyrical way. Until Li Yu, in the lyric way of the word appeared only straightforward way and gradually put the merits of the lyrical way to play out.

\subsection{Straightly Express Their Feelings and Naturally Unrestrained.}

The so-called straight expression, refers to their own thoughts and feelings to express frankly, rather than blindly relying on allusions, to carry out various modifications. During the late Tang and Five Dynasties, the text for a variety of modification and carving, which is a large part of the words of the lyrics tendencies, and in its emotional expression, but it is also more focused on the tactful lingering lyrical way. Until $\mathrm{Li} \mathrm{Yu}$, in the lyric way of the word appeared only straightforward way and gradually put the merits of the lyrical way to play out. From this point of view, Li Yu can be said to be the founder of the word straight expression, and the descendants of the heroic people are on top of it, this approach to the extreme. $\mathrm{Li}$ Yu words of a major artistic feature are "straight to express, naturally unrestrained." Among them, Yu Pingbo's evaluation of Li Yu's words is: "At the time, the word family is relying on the scene to express feelings, and only $\mathrm{Li} \mathrm{Yu}$ is straight to express their feelings, empty back, for the feelings of frank expression, it can be breathtaking" [1] The Such as Li Yu's "Wang Jiangnan", the whole Que word a total of five, of which only "tears" appeared on the word three times, that is, "how many tears", "and tears" and " Complex Heng Yi "is described as a picture of the face of tears," bowel more doubt "is the last sentence, summed up the first four tears and pain. Thus, Li Yu in these five words, there are four sentences are used to direct and indirect writing tears to express the feelings of pain, and this feeling from the souls of the heart directly, without any cover to emerge, and thus expressed The grievances and remorse of the poet. 
Another example is Li Yu's "Yu Mei", in this poem Li Yu will be vast endless worry and regret the performance of the most incisive, as the word described: "ask the king how many can worry, like a river spring to the east" The Li Yu here is completely a subjugation of the tone of the country, for the loss of the country that kind of sadness, as the surging river, as directly emerged. In the "Night of the night song" in the blurted out of "life cannot avoid the sadness", in the "black night cry" in the description of the "self is the growth of people hate the water long east." And so on to white to win, pure spirituality, the kind of tragic pain of the past, the kind of remembrance of the country's long hate, worry about the life of the great thorough understanding of all, as if everything is flowing from the heart and out, so natural and sincere and sincere. "Li Yu words this natural truth of the wind is the strong and fragrant" flower between the word "strong impact, write their own unique thoughts and feelings, since a style" [2]. It can be seen, Li Yu's words in the emotional expression never flicker, but the feelings of the most authentic, frank and clear expression, can be summed up as "straight expression, natural unrestrained" lyrical features, and this art The characteristics of the lyrics of the ideological and emotional performance of the vivid and vivid.

Whether it is from the emotional expression of the straightforward or from the emotional expression of the natural unrestrained, Li Yu's words are a whole heart to pour pure, deep feelings of the way, and for a king of the country, feel true, frank expression is rare. And Li Yu will own this natural unrestrained feelings into his words, it will make people more appropriate to the kind of deep feelings of his then, and then cause their own feelings of surging, causing resonance, to achieve a sense of empathy of the realm.

\subsection{Magnificent Hidden Resentment and Ethereal Ho Dang.}

Southern Tang Ci more to euphemism lyrical way of the main, and Li Yu words both empty spirit ho dang sense, is a beautiful and magnificent, magnificent and hidden pain combined aesthetic character. Such as Li Yu's "wave of sand", which "infinite country, when it is easy to see when difficult," this sentence shows the author for the subjugation of the remorse and at this time as a prisoner of the resentment feelings expressed. And "flowing water to spring also, heaven and earth" both a rigid and soft beauty, eyes began, feeling deep, highlighting a sense of magnificent. Li Yu's "Yu Chun floor", which both "Fengxiao blow off the water cloud free" the ethereal beauty, but also has a "to be riding on the horseshoe moon night," the dunk of the gas. So Wang Guowei in the evaluation of Li Yu words with "God show" to describe its overall style.

$\mathrm{Li}$ Yu's words are the inner spirit of the characters presented in their words. In addition to the main body that expresses the feelings, they also include the objects described by the lyric subject. Li Yu's "black night cry", which "naturally growers hate the water long East" a concise and powerful language, showing that he was a helpless, resentment feelings. And the most able to show the magnificent resentment, emptiness Haotang lyrical way is Li Yu's" broken son? 40 years home country ", one of the words" forty years home country, three thousand miles to the mountains and rivers ", not only reflects the words of the bitter state of mind at the time, but also the beauty of the words of the tragic embodiment of the most vividly "[3]. Although Li Yu describes his painful mountains and sorrows, but this rhetoric and profound feelings can also cause the reader's sympathy, is a tragic ho song, there is a sense of magnificent. And can be comparable to that is Yue Fei's "thirty fame and dust, soil, eight thousand miles of clouds and months," the majestic spirit. In addition, Li Yu's many words, such as "the country cannot afford to return to the first month of the Ming", "thousands of miles of cold mountains far", "cool cool days on the opening" and so on, this is almost close to the bold and ungrateful words, Li Yu words can be seen in the lyrical aspects of another artistic characteristics, that is, "magnificent hidden resentment, ethereal ho dang."

Li Yu's lyric is deep, deep and magnificent, and he expresses his feelings for a strong emotion in his country, which makes his words lack of strength and momentum in lyricism, which can also cause the reader to resonate. Its emotional and spiritual shock, making the readers filled with emotion. This is Li Yu wash the lead China, the feelings of the characters inside the refined expression, which reflects the empty heroes of the trend. 


\section{The Language Characteristics of Li Yu's Words}

$\mathrm{Li}$ Yu's words in the language and no gorgeous rhetoric, many are colloquial. Pay attention to the use of idioms and white sketches, coupled with his personal excellent writing ability, so that he can use the language in a simple natural language to achieve the whole word into the fascinating effect.

\subsection{Real Simple, Straightly Expression of the Spirit.}

Li Yu's words in the use of language and did not use too much elegant words or rhetoric, his lyric language has a "real simple, straightforward spirit" features, and even a lot of language belongs to a colloquial words, but it can The character of the word directly expressed. "This time Shen Qian Li Yu reputation as" very when the line of character ", meaning that $\mathrm{Li}$ Yu words with allusions and gorgeous rhetoric, its language simple Tiancheng, straight expression of the spirit" [4]. Such as "Sauvignon Blanc" in the "autumn wind, rain and the like" one, with a real and simple language will be the weather and the environment described at the time, both to allow the reader to feel the word close to life and simple side, while at the same time The poet was expressed at the time for the sigh of life.

Li Yu words often appear virtual words, such as "Yu Mei" for "again", "Utah", "just", "like" and other virtual characters; "Bodhisattva" in the "always fuddled" The word is simple, real and simple, although seemingly pale, but the expression of the feelings of sincere, romance is also very straightforward, will be The words of the heart for the former glory, honor, freedom and laughter directly to express it. And then "Xie Xin En" in the "too heavy" in the "and" the word, can strongly express $\mathrm{Li} \mathrm{Yu}$ for the homeland and loved ones deep thoughts of the feelings of the real and vivid description of the past, Chung Yeung and brother together, and now already left his own one. Li Yu's look at the "broken son": "40 years home country, three thousand miles to the mountains and rivers, Fengge Longlou Lianxiao Han, Yushu Qiongzhi smoke dream, a few had to know ..." "This word to Fu to describe the historical facts, remove the interest rate sustenance, the film on the past, the next film to ask this, magnificent, speech tragic, for the pain of the country, the wilderness of regret, The feeling of guards, prisoners of the storm, straight to express their feelings, feelings of a note down, there is no cover, the performance was most vividly. Another example is Li Yu's "Wang Jiangnan": "how many tears, broken face complex Heng Yi mind will Mo and tears that Fengsheng off to tears when blowing, intestinal broken more doubt. The total of five sentences, that is, there are three in the complaint "tears", and "broken face complex" is also writing tears vertical and horizontal face of the real thing, the last "bowel more doubt" is the first four tears and pain summary, In such a small order, the Ming with three "tears" and an indirect writing of tears to express the state of mind, from the spirit of the heart of the straight out, no cover. As a prisoner, the latter to indulge in their sorrow, to "intestinal off" show the pain, the word remorse, resentment of the personality characteristics are so clear and vivid. So, Li Yu's language features are straight and easy to know, and taste alcohol thinking long, straight lyrical spirit.

\subsection{Make Good Use of Saying, Metaphor Fine.}

Li Yu not only inherited and carried forward some of the classical poetry in the fine description of the way, and he for folk vocabulary and proverbs also studied, is a "water out of hibiscus, natural carving" pure beauty. Among them, "Yu Mei", "black night cry" and "Lang Taosha" is the successful use of the proverb. As in the "Yu Mei", Li Yu with "Chunhua", "Moon", "Dongfeng" and other common scenes, to describe their own heart sorrow and remorse. In the "black night cry" also did not quote any story, but the things purely white to describe the language style of narrative, such as "is sad, do not taste in the heart of the general" this sentence, without any decorative words, but through the simple language directly to his inner sadness reflected. "In the" Lang Taosha ", Li Yu with" rain "," water "," flower "," when it is easy to see when difficult "and the ancients often narrative feelings, through the sadness and depression linked to life through These common vocabularies reflect the most realistic thoughts and feelings of the poet at that time, thus expressing the complex and profound mental outlook of the poet "[5]. Another example is the "son of the night song" (how can I hate), Li Yu through the use of idioms and white language style to express their 
feelings, understand if words. The beginning of the word "worry about how can avoid" first open the poet on the most real thoughts and feelings, and the word the last sentence: "the past has become empty, but also a dream" is Li Yu feelings emerged, blurted out a deep feeling sincere words. Through the most simple and pure language, not only makes the poet's image fresh, and its expression of emotion is also appropriate.

In addition, Li Yu's other language features are for the metaphor, contrast, exaggeration and other tactical clever use. Such as "Yu Mei" in the last sentence "ask the king how many can worry about? Just like a river spring to the east", this sentence will $\mathrm{Li}$ Yu heart of the infinite subjugation of hate and the country of thinking, compared to the vast river, The infinite heart of the poet's mind as this surging river, endless rain. This kind of metaphor makes the "sadness" of this unspeakable, intangible thing, into the "river" this tangible thing, so that the poet was the kind of deep and real feelings of the special image of the show readers in front, but also allows readers to more deeply understand the words of the helpless and infinite sadness [6]. And then "meet", "Lin Hua thanked the spring red, too hasty" and "flowering flowers to spring," these two, Li Yu with "forest" and "water" to describe the "past good life has been "The use of" water long East "to describe the" human life hate "and so on, the image of the poet for the beautiful life has gone beyond the infinite expression of grief, but also let the reader deeply appreciate the word at the time emotion. Another example, "Qing Ping Le", Li Yu with white "fall plum" to describe their own cold at that time, "puzzle down plum like snow" this sentence is not only vividly described the state of plum blossom, but also the expression of the image The poet's inner world, very poetic beauty.

Li Yu early words to write his obsession with the luxury of the harem, such as "Huan Xisha": "red day has been high and three feet through, gold furnace times add gold beast, beauty dance point Jinchai slipped, drunk when twist flowers, the first word inherited the Southern Palace and the flowers between the words of the wind, but in the description of the characters than the flowers between the poet has a larger artistic summary strength.

\subsection{The Remorse of Cruel Reality.}

Li Yu's late words are mostly described "subjugation of the king of grievances" and "miss the homeland of sentimental" these aspects of the content. Because this period for the Northern Song Dynasty, Li Yu lived a captured, imprisoned subjugation of the king's life, which experienced the general emperor did not experience the great pain and imprisoned life experience. So the late $\mathrm{Li}$ Yu's words and pre-fancy luxury palace life and romantic life is much different, this time period of the word is full of a subjugated king's sadness, is a deep, sad and endless memories of a better life Prisoner's emotions. Such as "broken son" Li Yu on the three thousand mountains and rivers nation an instant death of the miserable and grief described. Which wrote the first word from the founding, the first few chapters of the history of the Southern Tang Dynasty and the country were described, and depicts his subjugation when the temple north of the situation. Which "a few had to know the song" to show $\mathrm{Li} \mathrm{Yu}$ in the loss of mountains and rivers do not hide their incompetence, he has been in a luxury palace life, where will know that there is war? And now the South Tang Siji was brutal war destroyed, $\mathrm{Li} \mathrm{Yu}$ at this time full of infinite sadness and remorse. Therefore, in the last few words of the first word, especially the "once vested, Shen Yao Pan temples" this sentence, Li Yu for their own from the emperor to order the prisoner's fate and the rapid changes in life were described, although Li Yu and did not have an in-depth description of the prisoners of life status, but only from the "Shen Yao Pan tempered" this sentence will be able to see that he was increasingly thin figure and can feel his loss of mountains and rivers nation's grievances. Li Yu itself is a sentimental person, and the loss of mountains and rivers after the prisoner is to enjoy their chest to see the sadness.

In addition, Li Yu later words are also written "miss the homeland of sentimental" and the "past good memories of life" and these works are Li Yu's true feelings, there is no false. "Such as" Yu Mei "in the" carved jade piles should be in the "this sentence is clearly expressed Li Yu for the homeland of thoughts, and the resulting infinite sentimental. This word fully express the word for the old words of the country of the nostalgia, with great artistic appeal "[8]. Li Yu's "son of the night song" (how can you avoid) the first word, "the dream of the return of the dream, feel double tears down," 
this sentence to express the lyrics of the feelings of the country, and "long note autumn clear" But also express the author of a remembrance of life at that time, but helpless "past has become."

\section{The Combination of Words of Li Yu Words}

The image of Li Yu's later words is sad and desolate.

\subsection{Beautiful and Happy Image - Early}

As Li Yu experienced the joy of the Southern Tang emperors, but also experienced the Northern Song Dynasty subjugation of the prisoners of life, so the image of its lyrics above is also very different.

$\mathrm{Li} \mathrm{Yu}$ early words of the image is joy and joy, such as "spring" image, in the "Son of the Night" (spring is to be early spring), "why the frequency of fun charm, ban spring late" here "spring" Word on behalf of the spring flowers in full bloom, a symbol of the beginning of life and vitality. Li Yu "spring" as a word, in the word meaning the social good and the growth of all things vitality.

"Moon" image, in Li Yu's pre-word, "month" symbolizes the beautiful, quiet environment and romantic good feelings. As in the "Yuling Spring", Li Yu described the palace after the end of the dinner scene. "To put horseshoe clear night" and "month" will be outside the moonlight is strong, and $\mathrm{Li} \mathrm{Yu} \mathrm{Xing} \mathrm{high} \mathrm{mood} \mathrm{to} \mathrm{show} \mathrm{it.} \mathrm{After} \mathrm{the} \mathrm{song} \mathrm{and} \mathrm{dance,} \mathrm{Li} \mathrm{Yu} \mathrm{longitudinal} \mathrm{ride} \mathrm{in} \mathrm{the}$ moonlight under the moonlight, that will be happy to indulge the excitement on the most vividly displayed in front of the reader.

"Dream" image, in Li Yu's pre-word, "dream" symbolizes a drunk dream life of the state, which also hurt the spring of pregnant with the meaning of Acacia. Such as "hi love warbler" in the "dream of grass thinking Yiyi" and "dream" there is the infatuation of the infatuation of love. And "mining mulberry" in the "sleepy sleepy dream" in the "dream" word is hurt the meaning of pregnant women.

"Fragrant" image, in Li Yu's pre-word, "incense" symbolizes a magnificent environment and the exquisite clothing exquisite woman exudes the wonderful aroma. Such as "Bodhisattva Man" in the "throw pillow Cuiyun light, embroidered clothing smell fragrant" in the "fragrance" will be the woman living in the beautiful environment and its charming beauty image show.

In short, because the main circle of life after $\mathrm{Li}$, narrowly confined to the Royal Palace, the contact of the characters and confined to the concubine palace E, karaoke dancers, coupled with the traditional text word, especially since the late Tang and Five dynasties since the influence of the school. Therefore, his early words have not yet jumped out of the fence of the factions, most of them are erotic words, a lot of image performance is mainly male and female Acacia, Palace complaining bizarre, from the situation and the palace of the enjoyment of life. Li Yu for such erotic words, Chen Tingzhuo said: "It is the romantic show man, the degree of loss of people" [9]. Predecessors are also the romantic wit, mistakenly the main person to summarize the words of $\mathrm{Li}$ Yu. As the Southern Tang Dynasty emperor Li Yu, in the face of a strong attack in the Song, unable to do anything. Therefore, in order to obtain spiritual comfort and relief, Li Yu in the pursuit of quiet and quiet, in an attempt to anesthesia their own ideas, forget the real life of all kinds of trouble, he indulged in the harem, perhaps not simply to seek excitement, but in the national strength of the decline, the family near the day, their own powerless and back to the day, save the country without the case, and produced a kind of helpless sense of loss, prompting him to forget the immediate difficulties, In the hairpin skirt song, stretch their feelings of depression, access to psychological balance, with the harem of the kind of flashy love to explain the political sense of loss. So, this time he is more for the love words to pass the time, distracting complex feelings. Li Houzhu these erotic words written vivid, made a high artistic achievement.

\subsection{Sadness Lingering, Sad and Desolate Image - Late}

$\mathrm{Li} \mathrm{Yu}$ in the later period is the descendants of the descendants of life, so he suffered the remorse of mountains and rivers, reduced to a country's captive of the sadness and the feelings of the homeland of the feelings of the performance in his later words. "Spring" image, in the "meet", "Lin 
Hua thank the spring red, too hasty" in the "spring" and "Lang Taosha" "flowing spring to go" in the "spring" word, the meaning of the tendency to a rush of life and the death of the king of remorse and the prisoners of prisoners still exist sadness. "Spring" in the "Spring Beauty", "Spring", although it is expressed on the surface of the "March spring flowers," this beautiful thing, but the whole point of view, the poet described the how good are these things and their end? So at this time the "spring" word has implied a desolate moral.

"Moon" image, in Li Yu's pre-word, "month" represents the lonely desolate living environment and state of mind. Such as "meet", "silent alone on the West Wing, such as the hook" in the "month" word to outline a sad autumn scenery of the screen, but also to express the words at this time lonely, desolate, cold state of mind. "Yu Mei" "the country cannot bear back to the first month of the Ming" in the "month" word to bring out the clear, cold, quiet, resentment of the mood, the words of the heart for the subjugation of sadness and homeland of thoughts and feelings show come out.

"Dream" image, in Li Yu's pre-word, "dream" represents a kind of homeland of thoughts and feelings of death. Such as "Wang Jiangnan" "how much hate last night in the dream" in the "dream" and "son of the night song" "national dream return, feel double tears down" in the "dream" word with a subjugation of the king the remorse and the thoughts of the homeland.

"Fragrant" image, in Li Yu's pre-word, "incense" word create a sad, lonely and desolate feeling. Such as "Yu Mei" (wind back to the small courtyard finish green) "candle incense dark painting in the deep" in the "fragrant" word to reveal the poet lonely no one complained about the state of mind.

$\mathrm{Li} \mathrm{Yu}$ later words, is written by a subjugation of the kingdom of the country's thinking, the performance of a prisoner's misery, full of sentimental sentiment. "But with the use of a variety of poetic images of the broad words of the mood to improve the ideological state of the word after the Lord in these words expressed in the life of grief, although only personal emotions and feelings, is written in tears Immortal work, with different images reflect the profound universality of human compassion, can cause the sympathy of readers of the past "[10]. When the country broke the death of the occasion, recite the "small building last night and the wind, the country cannot afford to return to the first month of the Ming." And other lyric words, will arouse the reader's sake, the customs of the situation: to move off the house, wandering from the people, chant "ask the king can have how many worry, like a river spring to the east," the sentence will feel how cordial it, out of their own hearts.

From the above discussion of the content and artistic characteristics of Li Yu's words, we can know that $\mathrm{Li} \mathrm{Yu}$ has played a role in promoting the development of the word. His creation, regardless of pre-and later, has always focused on the performance of life, straightforward spirit, full of true feelings, so that the word out of the "flower between the word" of the shackles, and truly become a poet used to express lyrical new poetry. Li Yu's $\mathrm{Ci}$ is a valuable cultural heritage in Chinese classical literature. Li Yu's words are written in tears of immortality, reflecting the universality of human compassion, can cause the reader's sympathy. As an outstanding poet, $\mathrm{Li} \mathrm{Yu}$ set the culmination of the five generations of the word, under the opening of the Song Dynasty song of the heyday, in the history of the development of the important position.

\section{References}

[1] Yu Pingbo. Ancient Huai book house [M]. Hong Kong: Hong Kong Book Publishing House, 1936, p. 65.

[2] Yue times. Dream of temporary meet - On Li Yu dream words[J]. Times Literature (the second half), 2015 (11): 16.

[3] Zhang Xinhong. Eternal word emperor - Li Yu's image appreciation[J]. Social Science Forum, 2015 (02): 19.

[4] Shen Qian. Ancient and modern words far [M]. Beijing: China Bookstore Press, 1650, p. 95.

[5] Peng Jieying. On Li Yu's creation of artistic conception[J]. Journal of Harbin Normal University 
Social Sciences, 2014 (12): 11.

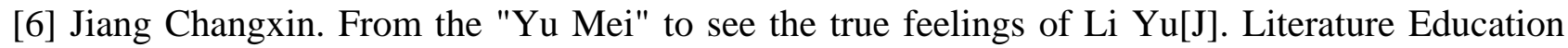
(on), 2014 (02): 10.

[7] Zhang Guijun. Li Yu later sentimental feelings[J]. Journal of Jilin Province Education College (early), 2014 (03): 24.

[8] Cai Yuqi. Li Yu's color change and psychological change [J]. Journal of Yancheng Teachers College (Humanities and Social Sciences), 2013 (10): 20.

[9] Zhao Tingzhuo. Li Yu's metaphor and its combination [J]. Hubei Normal University, 2013 (05): 21.

[10] Zhao Xueyong. On Li Yu's artistic characteristics[J]. Journal of Shaanxi Normal University (Philosophy and Social Sciences Edition), 2003 (06): 18 